\title{
Treatment of Head and Neck Area Pain by Multidisciplinary Approach with Template
}

\author{
Gi-Cheol Lee ${ }^{1}$, Won-Han Shin², Suhyun Park ${ }^{3}$, Hyun A Heo \\ ${ }^{1}$ Department of Oral and Maxillofacial Surgery, ${ }^{2}$ Department of Neurosurgery, Soonchunhyang University \\ Bucheon Hospital, ${ }^{3}$ Department of Oral and Maxillofacial Surgery, Bucheon St. Mary's Hospital, \\ The Catholic University of Korea, Bucheon, Korea
}

\begin{abstract}
Purpose: The headache is a symptom that various somatic or non-somatic disorders gives an effect to head and neck system. The neck and the shoulder pain is a common muscle pain that can not control and bothers the patient after chronic state. The headache and the neck and the shoulder muscle pain are treated with various conventional treatment methods. But, there are cases that symptoms did not resolve or increased in some clinical cases. And generally, the result of temporomandibular disorders (TMD) treatment is good. But, despite of a normal treatment was performed for TMD, there are cases that TMD symptoms did not resolved in clinical cases. In template clinic of Soonchunhyang University Bucheon Hospital, co-operative neurophysiologic treatment of Department of Neurosurgery and Dentistry are done for patients, who had head and neck pain or atypical symptoms that did not treated with various conventional treatment method such as surgery or medication etc.

Materials and Methods: Four hundred fifty one patients who have treated in the template clinic, Soonchunhyang University Bucheon Hospital, from January of 2006 to December of 2008 were subjected in this study.

Result: Overall average age was 31.9 years old. Ratio of numbers is $74.3 \%$ in female and $25.7 \%$ in male. The success rate of treatment in TMD symptom was $89.9 \%$, in headache was $88.8 \%$, in muscle pain was $81.6 \%$. Statistically significance of differences visual analogue scale evaluation between before and after had been treated patients who have over average grade headache was calculated by paired $t$-test. $P<0.05$ was considered significant.

Conclusion: We suggest the template appliance can be attempted for cases whose headache, the neck and the shoulder muscle pain and TMD are not resolved with various conventional treatment methods.
\end{abstract}

Key Words: Headache; Neurophysiology; Template; Temporomandibular disorders

Corresponding Author: Gi-Cheol Lee

Department of Oral and Maxillofacial Surgery, Soonchunhyang University Bucheon Hospital, 170, Jomaru-ro, Wonmi-gu, Bucheon 420-767, Korea

TEL : +82-32-621-5476, FAX : +82-32-621-5662, E-mail : drcleani@naver.com

Received for publication October 29, 2012; Returned after revision December 1, 2012; Accepted for publication December 8, 2012

Copyright $\odot 2012$ by Korean Academy of Dental Science

(c) This is an open access article distributed under the terms of the Creative Commons Attribution Non-Commercial License (http://creativecommons.org/licenses/ by-nc/3.0) which permits unrestricted non-commercial use, distribution, and reproduction in any medium, provided the original work is properly cited. 


\section{Introduction}

Head and neck area pain has various causes ${ }^{1)}$, and various treatment methods are suggested according to the cause. In clinical situations, however, some patients are dissatisfied with the result of treatment using the existing treatment methods, and some cases are difficult to classify as a specific type including headache, neck pain, shoulder pain, and temporomandibular disorder. Headache is one of the most common symptoms of temporomandibular disorder, which may cause tension headache $\mathrm{e}^{2,3)}$. Though various causes of headache have been suggested, there is a need to conduct more research studies to identify the clear cause of headache ${ }^{3)}$. Note, however, that most cases of tension headache are related to "stomatognathic disorder"; as a result, treatment of stomatognathic disorder including disorder of temporomandibular joint and masticatory muscle is a necessary or a minimal process to control tension headache ${ }^{4}$. In addition to the relationship between pain of the neck or facial muscles and tension headache, the relationship between migraine and neck muscles was suggested ${ }^{5}$. Many other researchers reported the relationship between headache and posture/muscle ache including pain of the neck and shoulder ${ }^{6}$ and improper posture of temporomandibular disorder patients ${ }^{6,7}$. Some papers insist that there is no relationship between posture and status of the stomatognathic system such as location of the jaw ${ }^{8}$, but many other papers report opposite results ${ }^{6,9)}$. For these reasons, we believe the adjustment of the stomatognathic system can affect the adjustment of posture ${ }^{6,10)}$ and pain of the head and neck area. Moreover, many stomatognathic disorder patients have multiple symptoms; thus suggesting the necessity of joint treatment by many departments related to the head and neck area ${ }^{2}$.

Based on these theories, we reviewed references and reported a case of patients treated for sharp pain or disorder in the head and neck area - which is not treated by existing methods such as surgery or medication, with joint treatment of neurosurgery and dental clinic using an intraoral device to control the stomatognathic system.

\section{Materials and Methods}

\section{Subjects}

The test subjects were the available patients treated during the period 2006 2008. The total number was 451 (female patients: 335 or $74.3 \%$; male patients: 116 or $25.7 \%$ ). The average age of female patients was 33.4 (9 78), and that of male patients was 27.4 (8 71). The overall average age was 31.9.

\section{Treatment Method}

A intraoral template device was used (Fig. 1).

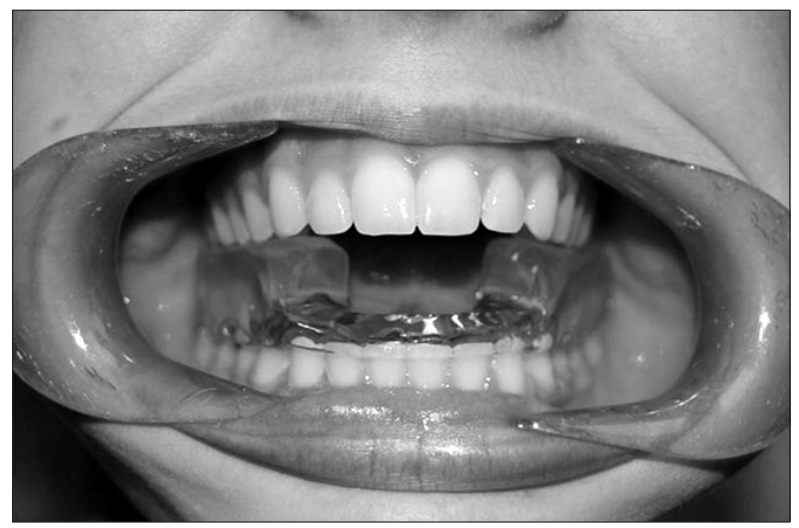

Fig. 1. Photograph of template installed in the mouth.

Table 1. Classification with symptoms

\begin{tabular}{lccc}
\hline & TMD & Headache & Muscle pain \\
\hline Female No. & 281 & 155 & 158 \\
Male No. & 96 & 32 & 49 \\
Total No. (\%) & $337(83.5 \%)$ & $187(42.2 \%)$ & $207(45.9 \%)$ \\
Female Ave. age (yr) & 32.2 & 34.6 & 34.1 \\
Male Ave. age (yr) & 25.3 & 27.4 & 28.6 \\
Total Ave. age (yr) & 30.5 & 33.5 & 32.9 \\
\hline
\end{tabular}

TMD: symptoms of temporomadibular disorders, Muscle pain: posterior neck pain, shoulder \& arm pain, Ave.: average. 
Template is a device used to tow the oral occlusal vertical dimension as 10 12 $\mathrm{mm}$. Its location was adjusted regularly to enable balanced posture, and patients used it for 10 12 hours daily when sleeping and doing light exercise.

\section{Classification of Symptoms}

$28.6 \%$ had only temporomandibular disorder, $12.6 \%$ had temporomandibular disorder and headache, $22.4 \%$ had only muscle pain, $19.9 \%$ had temporomandibular disorder and muscle pain, $2.9 \%$ had only headache, $3.6 \%$ had headache and muscle pain, and $10 \%$ had other symptoms (bad posture, dizziness, etc.).

$83.5 \%$ had temporomandibular disorder, $42.2 \%$ had headache, and $45.9 \%$ had muscle pain (Table 1).

\section{Evaluation Method}

The symptoms were evaluated using a questionnaire filled out at the first examination, regular

Table 2. Improvement's rates of symptoms

\begin{tabular}{lccc}
\hline & TMD & Headache & Muscle pain \\
\hline Female & $256 / 281(91.1)$ & $137 / 155(88.4)$ & $132 / 158(83.5)$ \\
Male & $83 / 96(86.5)$ & $29 / 32(90.6)$ & $39 / 49(79.6)$ \\
Total & $339 / 377(89.9)$ & $166 / 187(88.8)$ & $171 / 207(81.6)$ \\
\hline
\end{tabular}

TMD: symptoms of temporomadibular disorders, Muscle pain: posterior neck pain, shoulder \& arm pain.

Values are improved number/total number (\%).

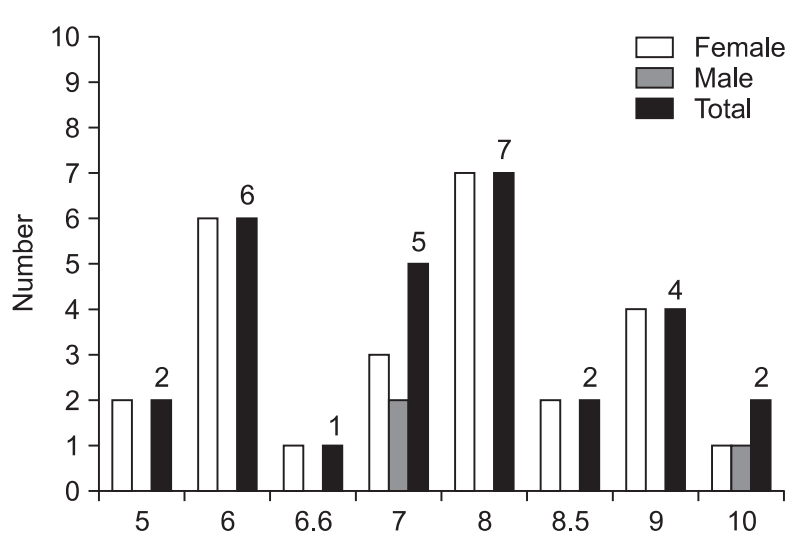

Fig. 2. Headache patients numbers before template therapy with VAS $(n=29)$. VAS: visual analogue scale. follow-up, and treatment. Patients answered 108 questions on symptoms in the interview survey (Appendix). The degree of each symptom was divided into very severe, severe, normal, and no symptom; change of very severe and severe symptoms into normal and no symptoms was regarded as improvement. Likewise, for headache patients, the degree of headache was surveyed before and after visual analogue scale (VAS) treatment.

\section{Result}

\section{Treatment Success Rate}

The treatment rate of temporomandibular disorder was $340 / 377$ patients $(89.9 \%)$, headache was 166/187 (88.8\%), and muscle pain including neck pain was $171 / 207$ (81.6\%) (Table 2).

\section{VAS Analysis}

Before the treatment, the average VAS was 7.5 (7.4 in the female group and 8 in the male group). After treatment, the average VAS was 2.4 (2.5 in the female group and 1.7 in the male group).

The improvement rate, i.e., VAS decreased to less than 4 , was $23 / 29(79.3 \%)$, and the rate of subjective symptom improvement such as decrease of headache frequency was 25/29 (86.2\%) (Figs. 2 and 3). After analyzing the VAS values before

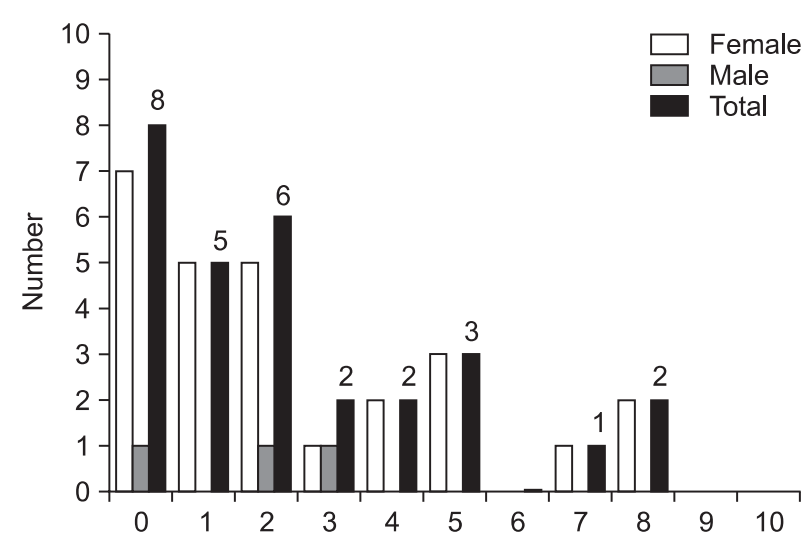

Fig. 3. Headache patients numbers after template therapy with VAS $(n=29)$. VAS: visual analogue scale. 
and after treatment with paired t-test, a statistical analysis, the difference was found to be statistically significant $(\mathrm{P}<0.05)$, and the treatment was proven to be effective.

\section{Discussion}

Literature suggesting the relationship between the neck muscle and occurrence of headache and migraine ${ }^{5)}$ report that there is a relationship between migraine, neck pain, and stiffness/tenderness of the neck area; convergence with the trigeminocervical nucleus between the trigeminal pathway and upper-cervical nociceptive pathway means the functional relationship between them for awareness of headache. Another paper reported that such convergence is the basis of the referred pain in the head and upper cervical region, and most referred pains generated after stimulating the neck centripetal nerve fibers occur in the occipital region, forehead, and orbital region ${ }^{11)}$. Yet another paper reported that the rate of headache attack occurrence is 34\% in the neck and shoulder, followed by $39 \%$ in the temporal-parietal region and $37 \%$ in the forehead $^{12)}$.

To reduce the pain of neck and shoulder, it is important to maintain proper posture at all times; preventing it requires correcting the posture and removing the various factors that may hurt the neck. If the pain is not removed despite such efforts, however, it means that the pain has reached a chronic state, and that the tension of muscle is deteriorating. As a result, not only conservative management but also professional treatments such as invasive treatment are required.

In literature, many factors related to temporomandibular disorder are suggested including genetic and acquired factors, change in the temporomandibular area and musculoskeletal system, arthritis, malocclusion, change in the blood vessel system, structural change such as change in the neuromuscular system, and mental factors such as stress and depression. Nonetheless, more than 2 factors are assumed to be related instead of having one factor at work. Non-invasive, conservative treatments are preferred in the treatment of temporomandibular joint disorder, and they have produced good results; for some patients who have severe and continuous pain or functional disorder and who are not treated by conservative treatment, surgical treatment may be performed. The device used in this study was template, and its background is different from stabilization splint, the most popular intraoral device ${ }^{13)}$. It is a device that considers the temporomandibular movement generated based on No. 1 and 2 cervical vertebrae as well as the movement generated based on the temporomandibular joint, according to the Quadrant theorem ${ }^{14,15)}$. Quadrant theorem is a theory on the motor mechanics of the jaw, not only occlusion (Fig. 4).

An intraoral device has been used to treat temporomandibular disorder. Template leads to the improvement of temporomandibular disorder by reducing pressure on the temporomandibular joint and eases pressure on the cervical vertebral portion by pushing the upper jaw (two parts connected to each other). It is a concept wherein a change made in the stomatognathic system using a device taller than the normal splint will be extended to the area near the head and neck area and the central nervous system. By using an intraoral device by themselves, patients need not be hospitalized, and pressure on the cervical vertebrae can be reduced by using it for hours per day during a certain period ${ }^{16)}$. Though some researchers doubt this theory, many researchers reported mandibular movement and coordination exercise of the cervical vertebrae after analyzing the functional movement of muscles or reflection of nerves ${ }^{17-21)}$. Based on these reports, considering that fact that mandibular movement and coordination exercise of the cervical vertebrae are connected functionally, the use of an intraoral device designed to increase the vertical diameter is 
assumed to increase the masticatory muscles related to mandibular movement, relax the neck muscles connected to the lower jaw, and consequently relieve muscle pain and tension-type pain caused by the contraction of the surrounding muscles ${ }^{14-16)}$. This report also assumed that the increase of masticatory muscle leads to the relaxation of muscles in the head and neck area based on the treatment result of neck pain and shoulder pain. In addition, most cases wherein the template was applied had a symptom that progressed, but the treatment result of temporomandibular disorder was good.

Harmful stimulation in the cervical portion is delivered to the trigeminal subnucleus caudalis not only through the trigeminal nerve but also via various nerves (Fig. 5). In other words, headache as one of the head and neck area pains passes the caudate nucleus of the trigeminal subnucleus caudalis regardless of its cause (Fig. 6) ${ }^{22-24)}$.

By using an intraoral device to increase the vertical diameter, masticatory muscles for mandibular movement are increased and stretched. As a
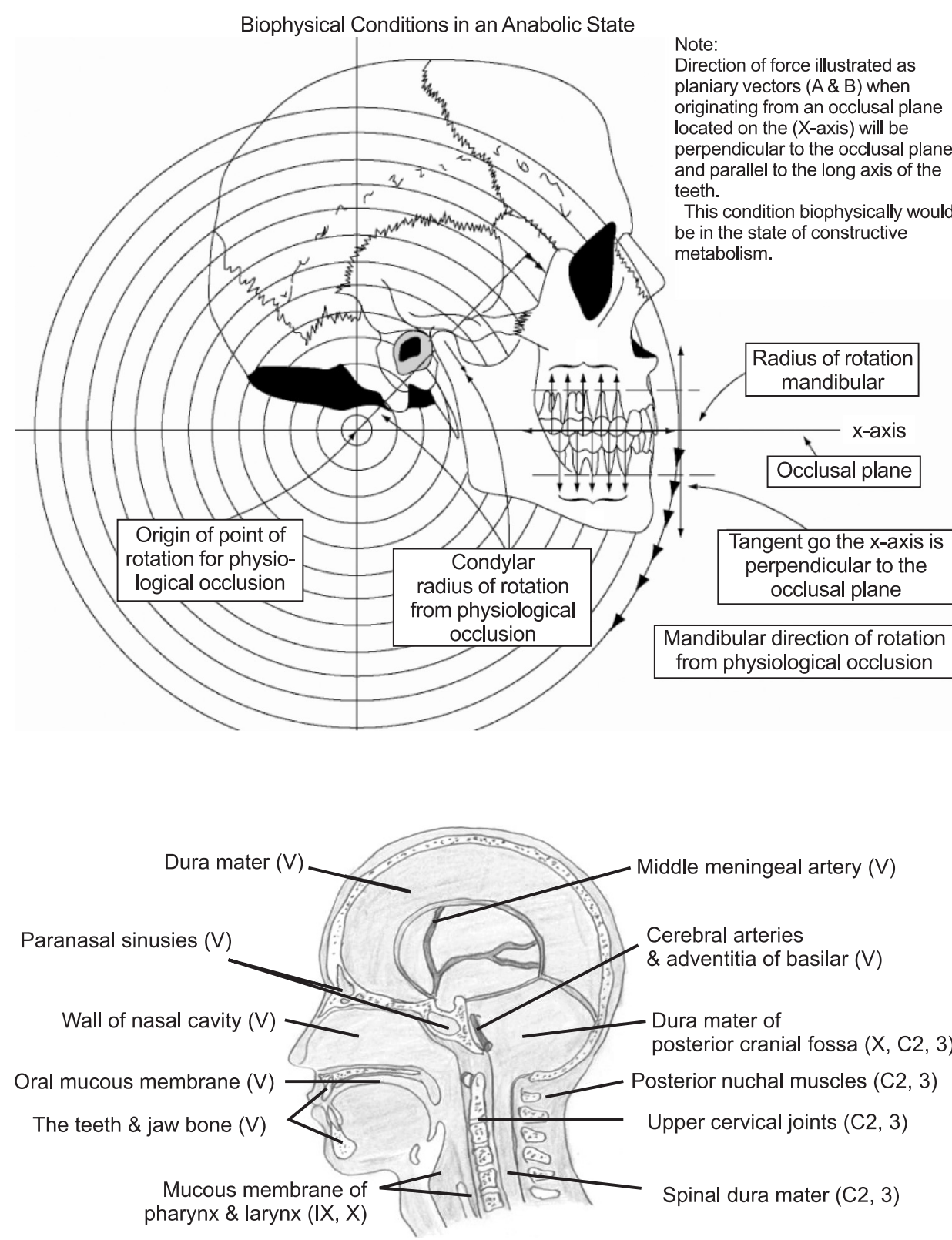

Fig. 4. Quadrant theorem for head and neck area movement as suggested by $\mathrm{Dr}$. Guzay: based on the physical analysis of mandibular and neck movement (Quadrant theorem: Physical analysis theory on mandibular movement. Narae Publishing, 2011 Seoul).

Fig. 5. Harmful receiving area of spinal trigeminal nucleus. Between brackets are nerves that deliver pain. $\mathrm{V}$ : 5 th cranial nerve, IX: 9th cranial nerve, $X$ 10th cranial nerve, $C$ : cervical nerve. 


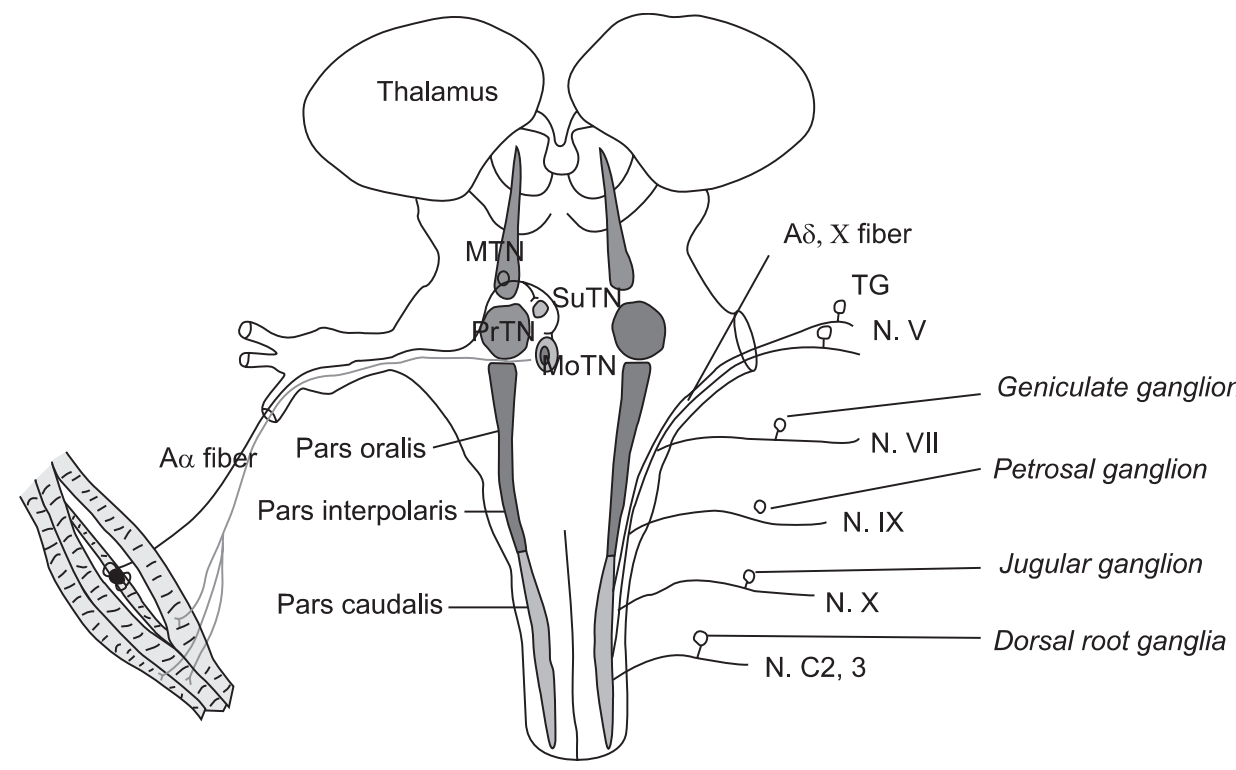

Fig. 6. Spinal trigeminal nucleus consists of pars oralis, pars interpolaris, and pars caudalis. Nociceptive sense is delivered to pars caudalis. MTN: mesencephalic trigeminal nucleus, SuTN: supratrigeminal nucleus, PrTN: trigeminal pontine nucleus, MoTN: trigeminal motor nucleus, TG: trigeminal ganglion, $\mathrm{N}$.: nerve.

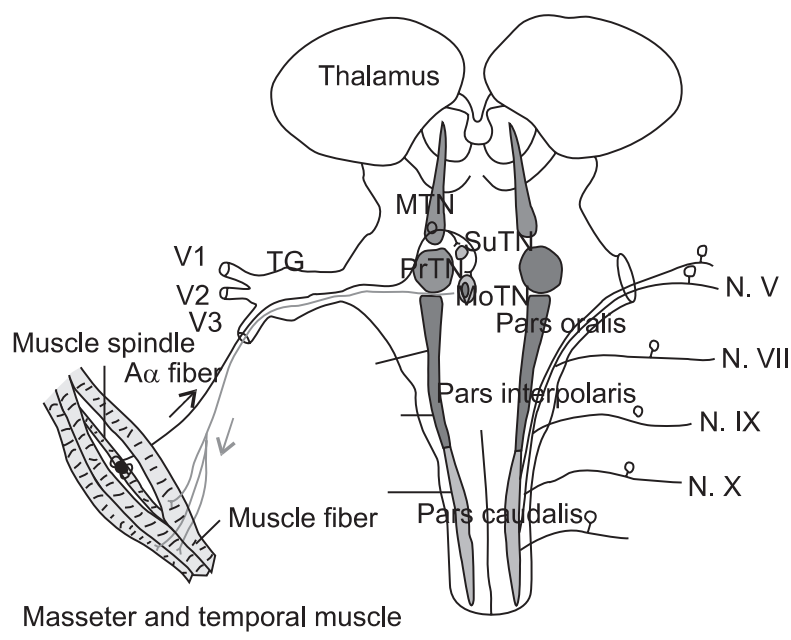

Fig. 7. Circuit diagram of the delivery process from the muscle spindle of the masticatory muscle to the mesencephalic trigeminal nucleus and trigeminal motor nucleus. MTN: mesencephalic trigeminal nucleus, SUTN: supratrigeminal nucleus, PrTN: trigeminal pontine nucleus, MoTN: trigeminal motor nucleus, TG: trigeminal ganglion. N.: nerve.

result, the conduction of proprioceptive sense of muscle spindles in the masticatory muscle stimulates trigeminal nucleus neurons in the brain stem's midbrain $^{23-25)}$. The direct delivery of muscle spindles' signal in the brain and the existence of masticatory muscles' motor circuit are clinically significant (Fig. 7) ${ }^{25}$. In short, signals delivered to trigeminal nucleus neurons not only form a circuit with the trigeminal motor nucleus and participate in masticatory movement but also connect with the lateral medullary reticular formation, VI lamella of the C1 C3 spinal segment, Supra-, Inter-, juxtatrigeminal regions, and cerebellum ${ }^{25)}$. In addition, because signals of muscle spindles reportedly affect trigeminal thalamic fibers ${ }^{26}$, the starching of masticatory muscle can be assumed to change the delivery process of pain. There are some research studies on the relationship between the trigeminal nerve circuit and migrain ${ }^{27,28)}$. In this research, the treatment rate of headache was $88.8 \%$, and the improvement rate of VAS for headache severer than the medium level was $80 \%$. Therefore, since the template treatment used in this research is a conservative method rather than surgery or medication, it can be a treatment for chronic headache based on more research and analyses. In addition, the basis of the suppression mechanism of other pains is the connection between the trigeminal nerve and nucleus locus ceruleus ${ }^{29,30)}$, and trigeminal nerve has the biggest and most extensive connectivity in the brain stem; hence the need for more research on the trigeminal nerve. 


\section{Conclusion}

The result of this study will contribute to understanding the symptoms of patients more clearly based on neurophysiological evaluation and analysis of patients of head and neck area pain. Managing patients' symptom with various methods based on such evaluation will increase the efficiency of treatment and broaden its range; hence the need to pay more attention to the role and function of trigeminal nerve and conduct the relevant research. So, we suggest the template appliance can be attempted for cases whose headache, the neck and the shoulder muscle pain and TMD are not resolved with various conventional treatment methods. We see the need to analyze complex factors and conduct in-depth research by reviewing papers and clinical results and a relationship between posture and stomatognathic system.

\section{References}

1. Chung SC, Kim YK. Orofacial pain and temporomandibular disorders. 2nd ed. Seoul: Shinhung Co.; 2006.

2. Lee HK, Hong JP, Chun YH. Orofacial evaluation of tension-type headache in dentistry. Korean J Oral Med. 2004; 12: 395-406.

3. Auh QS, Hong JP, Chun YH. Clinical symptom of tension-type headache and temporomandibular disorders in pain. Korean J Oral Med. 2004; 12: 35365.

4. Olesen J, Tfelt-Hansen P, Welch KMA: The headaches. New York: Raven Press; 1993; 527-30.

5. Shevel E, Spierings EH. Cervical muscles in the pathogenesis of migraine headache. J Headache Pain. 2004; 5: 12-4.

6. Cuccia A, Caradonna C. The relationship between the stomatognathic system and body posture. Clinics (Sao Paulo). 2009; 64: 61-6.

7. Hackney J, Bade D, Clawson A. Relationship between forward head posture and diagnosed internal derangement of the temporomandibular joint. J Orofac Pain. 1993; 7: 386-90.

8. Michelotti A, Buonocore G, Farella M, Pellegrino G, Piergentili C, Altobelli S, Martina R. Postural stability and unilateral posterior crossbite: is there a relationship? Neurosci Lett. 2006; 392: 140-4.

9. Gangloff P, Perrin PP. Unilateral trigeminal anaesthesia modifies postural control in human subjects. Neurosci Lett. 2002; 330: 179-82.

10. Sakaguchi K, Mehta NR, Abdallah EF, Forgione AG, Hirayama H, Kawasaki T, Yokoyama A. Examination of the relationship between mandibular position and body posture. Cranio. 2007; 25: 237-49.

11. Bogduk N. Anatomy and physiology of headache. Biomed Pharmacother. 1995; 49: 435-45.

12. Yoon JW, Moon DE, Yang SY, Park CM. Therapeutic effect of the patients with chronic migraine in pain clinic. J Korean Pain Soc. 2004; 17: 146-52.

13. Japanese Society for Temporomandibular Joint. Temporomandibular disorders. 1st ed. Seoul: Narae Publishing Inc.; 2004.

14. Guzay CM. Introduction to the quadrant theorem. Basal Facts. 1976; 1: 153-60.

15. Guzay CM: Quadrant theorem: a viewable biophysical analysis of prosthodontia, orthodontia, T.M.J. disorders. Chicago: D.D.S. Publications; 1979.

16. Maehara K, Sato S, Takada F, Ito H, Matsui T, Ueda T, Takesada M, Nakajima A, Tsuruhara T, Hase Y. A template therapy approach for non-specific complaints. Basal Facts. 1986; 8: 22-35.

17. Azuma Y, Maehara K, Tokunaga T, Hashimoto M, Ieoka K, Sakagami H. Systemic effects of the occlusal destruction in guinea pigs. In Vivo. 1999; 13: 519-24.

18. Eriksson PO, Häggman-Henrikson B, Nordh E, Zafar H. Co-ordinated mandibular and head-neck movements during rhythmic jaw activities in man. J Dent Res. 2000; 79: 1378-84.

19. Koolstra JH, van Eijden TM. Functional significance of the coupling between head and jaw movements. 
J Biomech. 2004; 37: 1387-92.

20. Eriksson PO, Zafar H, Nordh E. Concomitant mandibular and head-neck movements during jaw opening-closing in man. J Oral Rehabil. 1998; 25: 859-70.

21. Serrao M, Rossi P, Parisi L, Perrotta A, Bartolo M, Cardinali P, Amabile G, Pierelli F. Trigeminocervical-spinal reflexes in humans. Clin Neurophysiol. 2003; 114: 1697-703.

22. FitzGerald MJT, Folan-Curran J: Clinical neuroanatomy and related neuroscience. Edinburgh, New York: W.B. Saunders; 2002.

23. Kiernan JA, Barr ML: Barr's the human nervous system: an anatomical viewpoint. Philadelphia: Lippincott Williams \& Wilkins; 2005.

24. Lee WT, Park KA: Medical neuroanatomy. 2nd ed. Seoul: Korea Medical Book Publisher; 2008.

25. Lazarov NE. Neurobiology of orofacial proprioception. Brain Res Rev. 2007; 56: 362-83.

26. Allen GV, Pronych SP. Trigeminal autonomic pathways involved in nociception-induced reflex cardiovascular responses. Brain Res. 1997; 754: 26978.

27. Lambert GA, Hoskin KL, Zagami AS. CorticoNRM influences on trigeminal neuronal sensation. Cephalalgia. 2008; 28: 640-52.

28. DaSilva AF, Granziera C, Tuch DS, Snyder J, Vincent M, Hadjikhani N. Interictal alterations of the trigeminal somatosensory pathway and periaqueductal gray matter in migraine. Neuroreport. 2007; 18: 301-5.

29. Couto LB, Moroni CR, dos Reis Ferreira CM, Elias-Filho DH, Parada CA, Pelá IR, Coimbra NC. Descriptive and functional neuroanatomy of locus coeruleus-noradrenaline-containing neurons involvement in bradykinin-induced antinociception on principal sensory trigeminal nucleus. J Chem Neuroanat. 2006; 32: 28-45.

30. Tsuruoka M, Matsutani K, Maeda M, Inoue T. Coeruleotrigeminal inhibition of nociceptive processing in the rat trigeminal subnucleus caudalis. Brain Res. 2003; 993: 146-53. 
Appendix. Academy for Medical and Dental Co-operation Questionnaire

\begin{tabular}{|c|c|c|c|c|c|c|c|c|c|c|c|c|c|c|c|}
\hline 신체상태(A) & & $=1$ & & 신체상태(A) & 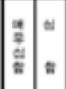 & $=1$ & & 신체상태(A) & & $\begin{array}{l}4 \\
= \\
=\end{array}$ & $=$ & 정신상태(B) & $=$ & $=$ & \\
\hline 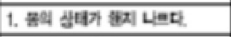 & & & & 30. 에류 군 & & & & 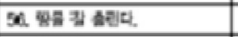 & & & & 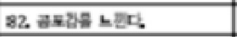 & & & \\
\hline 2. 배베 피로하다. & & & & 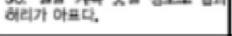 & & & & 57. 샘에 노로. & & & & 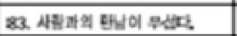 & & & \\
\hline 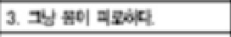 & & & & 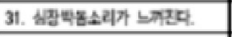 & & & & 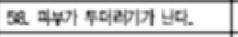 & & & & 24. 선경이 샏바하도. & & & \\
\hline 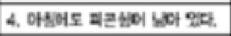 & & & & 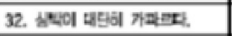 & & & & 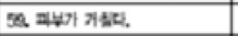 & & & & 85. 네게 늡옴느를. & & & \\
\hline 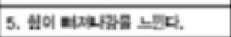 & & & & 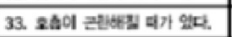 & & & & 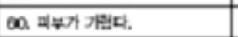 & & & & 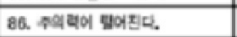 & & & \\
\hline 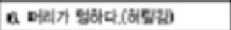 & & & & 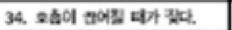 & & & & 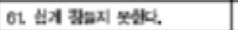 & & & & 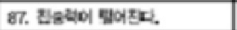 & & & \\
\hline 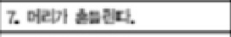 & & & & 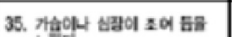 & & & & 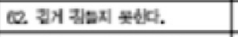 & & & & 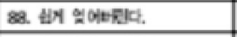 & & & \\
\hline 8. 머리가 어지혬다. & & & & 넨다. & & & & 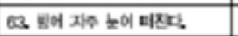 & & & & 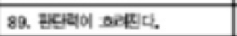 & & & \\
\hline a 더리가 버프다. & & & & 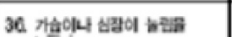 & & & & 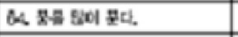 & & & & 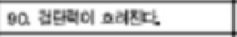 & & & \\
\hline 10. 더리가 부겸다. & & & & 4 나다. & & & & 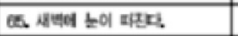 & & & & 91. 저븜믈 배리지 붓연다. & & & \\
\hline 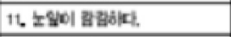 & & & & 37. 손토이 펴라다. & & & & 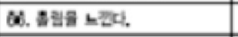 & & & & 92. 서이기 하 현대. & & & \\
\hline 12 느이 부세다. & & & & 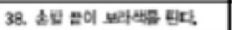 & & & & \multirow{3}{*}{ 정신상태(B) } & & & & 83. 억투이 헐다. & & & \\
\hline 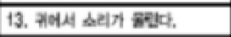 & & & & 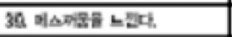 & & & & & & & & 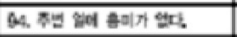 & & & \\
\hline 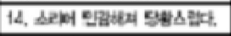 & & & & 40. 구툐 핸다. & & & & & & & & 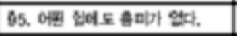 & & & \\
\hline 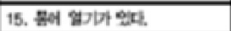 & & & & 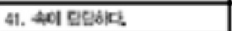 & & & & 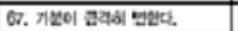 & & & & 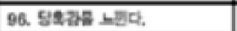 & & & \\
\hline 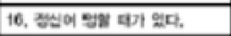 & & & & 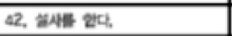 & & & & 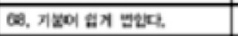 & & & & 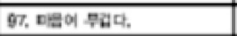 & & & \\
\hline 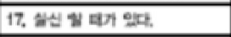 & & & & 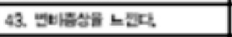 & & & & 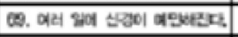 & & & & 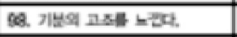 & & & \\
\hline 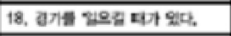 & & & & 44, 싀푹이 연드. & & & & 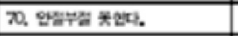 & & & & 90. 기분이 녀무 슷도 & & & \\
\hline 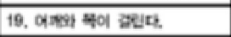 & & & & 닝, 해가 때리다. & & & & 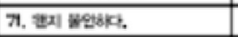 & & & & \multirow{2}{*}{ 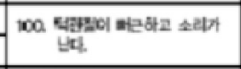 } & & & \\
\hline 20. 다리가 부겸드. & & & & 46 실이 Nㅏㄷㅗ. & & & & 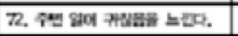 & & & & & & & \\
\hline 21. 가슴이 토맣ㄷㄷ. & & & & 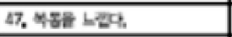 & & & & 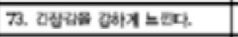 & & & & 106, 늘 암이 아프드, & & & \\
\hline 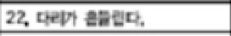 & & & & 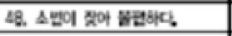 & & & & 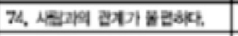 & & & & 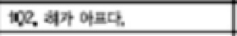 & & & \\
\hline 23. 보이 홀 협 나룬다. & & & & 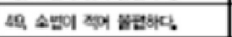 & & & & 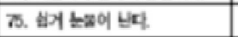 & & & & 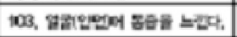 & & & \\
\hline 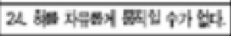 & & & & 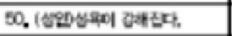 & & & & 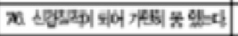 & & & & 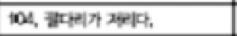 & & & \\
\hline 25. 논이 때레다. & & & & 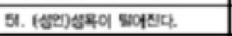 & & & & 77. 심검베웍이 얼다 & & & & 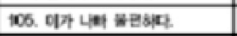 & & & \\
\hline 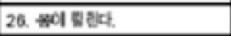 & & & & 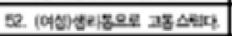 & & & & 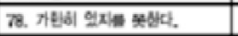 & & & & 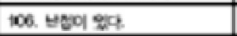 & & & \\
\hline 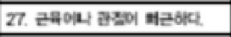 & & & & 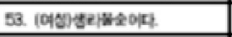 & & & & 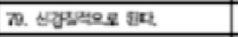 & & & & 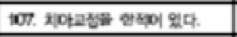 & & & \\
\hline 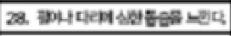 & & & & 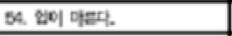 & & & & 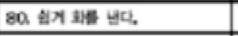 & & & & \multirow{2}{*}{ 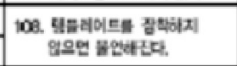 } & & & \\
\hline 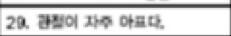 & & & & 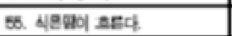 & & & & 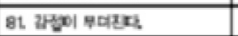 & & & & & & & \\
\hline
\end{tabular}

